\title{
A review of key development areas in low-cost packaging and integration of future E-band mm-wave transceivers
}

\author{
Tinus Stander \\ Carl and Emily Fuchs Institute for Microelectronics \\ Dept. EEC Engineering, University of Pretoria \\ Pretoria, South Africa \\ tinus.stander@ieee.org
}

\begin{abstract}
With an ever increasing number of broadband applications in sub-Saharan Africa, mm-wave point-to-point networking has the potential to fill a niche in communications network architectures. Widespread adoption of this technology would benefit from conventional RF soft substrate integration and packaging, as opposed to system-on-chip or thick film processes. A review on the state-of-the-art in E-band soft substrate systems reveals significant reliance on MMICs. We propose that hybrid integration of active devices with off-chip passives, as well as better integration of active components in SIW, will lead to better performing E-band systems in soft substrates. Specific enabling techniques from the microwave domain are identified.
\end{abstract}

Keywords - electronics packaging; millimeter wave communication; millimeter wave devices; millimeter wave technology; radio transceivers

\section{INTRODUCTION}

Limited ICT development in developing countries has been shown to restrict economic growth, with poor access to broadband services cited as a major contributor [1]. A major study into these shortcomings in sub-Saharan Africa's broadband connectivity [2] found that backhaul networks are one of the reasons that broadband is not widely available in the region and remains a niche product, affordable by only a few. For this, and other reasons, the indigenous development of future wireless technologies is becoming an important ICT policy point for developing countries [3].

This limitation is relevant even in the developed world, where ever increasing subscriber numbers and limited backhaul connectivity capacity have already impacted on the quality of service offered by mobile networks [4]. Augmentation of backhaul capacity is often hampered by the roll-out cost of DSL or 10 Gbps fiber optic lines, not only not only due to the cost of the fiber itself (up to $10,000 € / \mathrm{km}$ ) but also the roadwork and trenching required to install the fiber (up to $300,000 € / \mathrm{km})[5]$.

Millimetre-wave $(30-300 \mathrm{GHz})$ transceivers have received widespread commercial adoption in imaging and automotive RADAR applications due to small size and sharp image resolution over short distances [6]. However, due to the availability of broadcast spectrum above $30 \mathrm{GHz}$ (compared to traditional GSM, LTE and $2.4 \mathrm{GHz}$ ISM bands, Fig. 1) attention is being turned to the underutilised mm-wave spectrum for future wireless communications applications, with mm-wave point-to-point links employed as a solution to lastmile fiber replacement or augmentation [5]. In this role, the E-

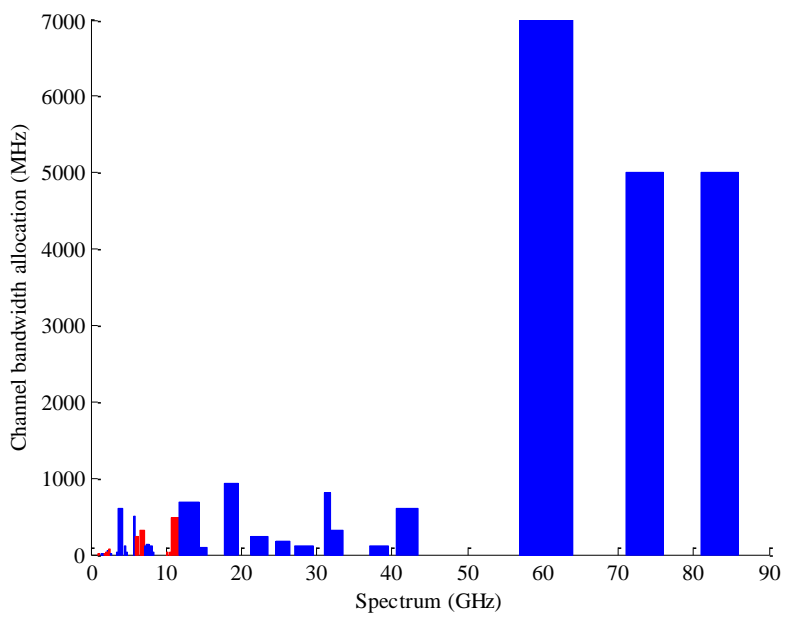

Figure 1: ICASA licensed spectrum and per channel bandwidth allocation [7] Fully allocated bands are indicated in red.

band spectrum at the 71-76 and 81-86 GHz ITU-regulated bands [7] have received significant interest. The neighboring 92-95 GHz band covers a local minimum in atmospheric attenuation with properties comparable to that of the $\mathrm{Ka}$ RADAR band [8] but has received less attention due to far stricter statutory regulations [4].

Although future 5G mobile networks [9] is the prime application example of E-band point-to-point links, a more immediate role may be in smart grid monitoring and control [10][11]. It is envisaged that real time load conditions, insulator degradation, line faults, motion and even widespread video monitoring [12-14] will form part of such a network, as opposed to the traditional telemonitoring and telecontrol of only the high voltage lines. Smart metering alone will require more than $100 \mathrm{Mbps}$ transmission per 100,000 customers [15], which is well beyond the capabilities of current VHF and UHF 
radio links [16], conventional power line communications (2 $3 \mathrm{Mbps}$ ) or other radio standards such as WiMAX (75 Mbps), whilst pushing the capabilities of $100 \mathrm{Mbps}$ broadband power line communications [17] and (expensive to lease) LTE networks [13].

Although there are numerous areas in which further development is needed to make these systems more costeffective (both to develop and to produce), this paper will focus on system integration. The state-of-the-art in E-band transceiver system integration is reviewed Section II, where two key areas of further system integration development are defined. Hybrid system integration in soft substrates is then discussed in Section III, with Section IV covering integration of active devices in substrate integrated waveguide (SIW) in Eband.

\section{A REVIEW OF E-BAND SYSTEM INTEGRATION APPROACHES}

The most compact solution to E-band transceivers is to market them as full systems-on-chip (SoC), as has been demonstrated in 100nm GaAs [18-20], 40nm GaN [21][22], 40nm CMOS [23] and 130nm SiGe BiCMOS [24][25] technologies. Though compact and efficient, the non-recurring cost associated with SoC does not make it a feasible option for low volume production or in development environments with limited prototyping resources. Another significant drawback to complete on-chip system integration is the high losses and low self-resonant frequencies of the passive circuitry surrounding the active transistors on the semiconductor die [26] at mmwave frequencies, an effect exacerbated by nearfield interaction between the on-chip passive and the host substrate after mounting [27]. Typical unloaded quality factors (Qfactors) for on-chip resonators at E-band frequencies have been demonstrated only up to 83 [28] for compound transmission line resonators, 43 for shielded transmission line resonators [29], 25 for single transmission line resonators [30] and below 15 for LC tank resonators [31]. This compares poorly with achievable unloaded Q-factors at mm-wave frequencies of over 200 in SIW [32], over 3,000 for ceramic dielectric resonators [30] and Q-factors in excess of 75,000 for machined waveguide resonators [33].

E-band system integration with off-the-shelf components traditionally makes use of pre-packaged components in WR-12 rectangular waveguide [34][35]. The majority of commercial systems [36][37] and subsystems [38][35][39] are also marketed as WR-12 integrated waveguide assemblies. There are, however, numerous mm-wave transceiver applications where waveguide system integration is not feasible due to size, weight or cost constraints [40] and if mm-wave transceivers are to be rolled out in large quantities, they need to be integrated in a compact fashion and produced at low cost without sacrificing performance [41]. This dominance of waveguide packaging contrasts with microwave systems [42-44] where board level integration is commonplace for a wide variety of systems.

In recognition of a this new need for accessible board level E-band system packaging, more suppliers are moving towards supplying active components (amplifiers, mixers, voltage controlled oscillators (VCOs) and others) as off-the-shelf components ([45-48]) for multi-chip module systems [49]. Since standard QFN-type surface mount technology (SMT) packaging has a feasible upper limit of $45 \mathrm{GHz}$ [50], these offthe-shelf components are usually supplied as bare dies suitable for flip-chip bonding at mm-wave frequencies [51][52]. More experimental packaging technologies such as waveguide apertures, micro-coax and through-wafer vias have also been proposed [50] but not yet commercially adopted. With the availability of commercial RF substrates that perform well at E-band and W-band frequencies [32], it should come as no surprise that board-level E-band transceiver developments are performing amicably [49][41][53][54]. There are, however, still shortcomings in the state-of-the-art, and addressing these shortcomings may lead to improved overall system performances through, amongst others, minimizing interconnect attenuation and reducing the number of on-chip low Q-factor passives.

\section{A. Hybrid component integration in soft substrates}

Despite the advantage of having access to low loss packaging and integration media for passives layouts, mmwave multi-chip module development still uses monolithic microwave integrated circuits (MMICs) as components [55] in multi-chip modules (Fig. 2). These devices all rely on extensive transmission line on-chip matching, dividing / combining and other passive networks [56] which may both attenuate significantly (due to the previously noted low Qfactors for passives) and cause unwanted radiation [57]. This loss translates into the degradation of noise figure in E-band low noise amplifiers (LNAs) [58], increase in phase noise of oscillators [59] and reduced efficiency of power amplifiers [31].

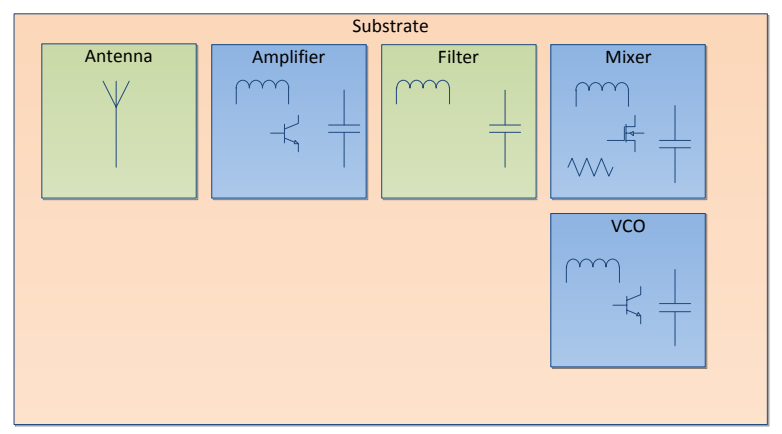

Figure 2: Conventional approach to multi-chip module system integration.

In the microwave domain, discrete transistors (commonly GaAs pHEMTs and GaN HEMTs [60]) are readily available off-the-shelf and are often used for custom circuit designs with off-chip passives. Following the microwave model, an alternative system layout method for future E-band transceivers is hybrid packaging of the system's different circuits (Fig. 3), whereby the system integrates on-chip semiconductor components with off-chip passive components (inductors, capacitors, resonators and other transmission line components [61]) that may even form part of the packaging itself [62]. Even though the principle of full-system distributed packaging has only been demonstrated up to $40 \mathrm{GHz}$ [63], this approach is feasible at much higher frequencies given the availability of the 
necessary interconnects [52] with below $0.3 \mathrm{~dB}$ degradation in performance [56].

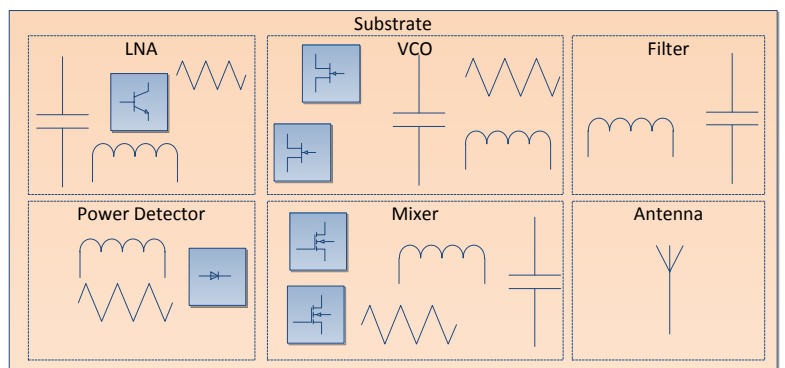

Figure 3: System integration architecture with off-chip passives and several discrete semiconductor device dies.

An extension on the multi-die configuration in Fig. 3 would be to have all the system's active devices clustered on a single die (Figs. 4 and 5) with all the system's passive components distributed around that single die. Typical active components could include discrete lumped transistors for LNA / PA design, but also cross-coupled transistor pairs and varactors for VCOs, diodes for power detection, and other common standard components in custom ICs. Although this configuration would prohibit the application of multiple semiconductor technologies (eg. InP for LNAs and GaN for PAs) in the same system, it would allow for more compact system integration, fewer onchip / off-chip interconnects, and provide a single point of power regulation.

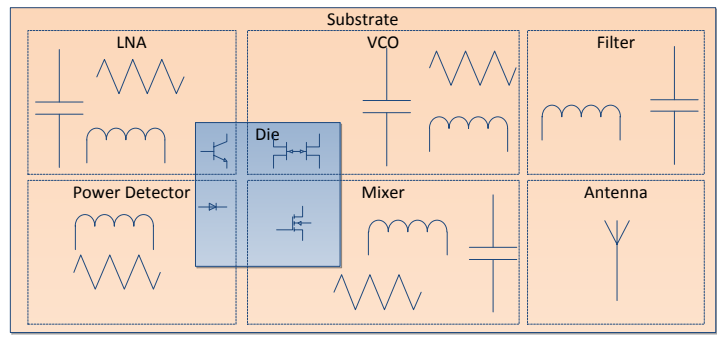

Figure 4: System integration with a single common die and passives distributed around the die

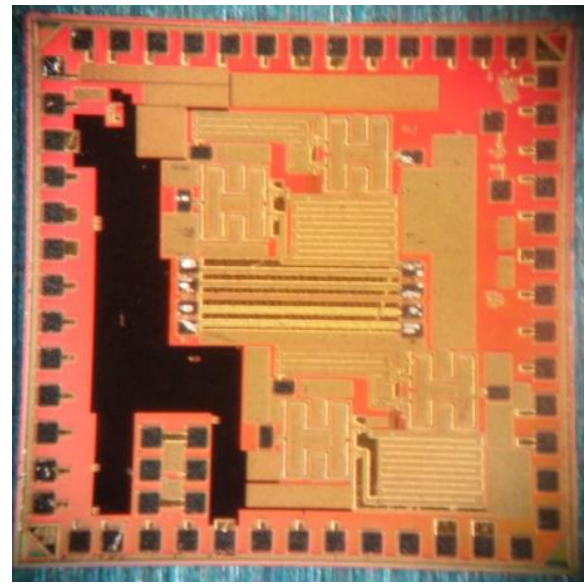

Figure 5: Single die, multi-device chip, manufactured in IBM 8HP 130nm SiGe BiCMOS. Die carries multiple filters, switched delay lines, single transistor for off-chip matched LNA, an oscillator core and a voltage regulator.

\section{SOFT SUBSTRATE INTEGRATED WAVEGUIDE SYSTEMS}

Substrate integrated waveguide (SIW, Figs. 6 and 7) has been successfully used for integrating E-band passive devices such as antennas and feed networks [64] filters [32] directional couplers [65] and even for partial system integration [41] in conventional RF soft substrates (as well as liquid crystal polymers [66] and low-temperature co-fired ceramics [67], though at higher cost). A significant shortcoming in the stateof-the-art in SIW system integration is connecting active components into the SIW RF path (as is easily done with planar RF transmission media such as coplanar waveguide or microstrip). The conventional approach is to transition from SIW to a planar medium with an exposed signal conductor, such as coplanar waveguide (CPW) [68] and then to integrate the active components in the planar medium. Although a recent paper has shown that this transition is unnecessary and that dies can be wirebonded directly to SIW, even at mm-wave frequencies [69] examples of coherent co-design of complementary active-passive circuits (such as amplifier matching or oscillator tanks) is still absent at E-band.

The president for this integration has, however, already been set for amplifier matching (using SIW discontinuities as matching elements [70]) and VCO design [71] at microwave frequencies, but this interconnected co-design has not yet been applied to other required active system components such as calibration noise sources, mixers, multipliers, switches, and others. Once designs for these devices are published and readily available to design engineers, fully SIW integrated Eband systems may emerge on the market.

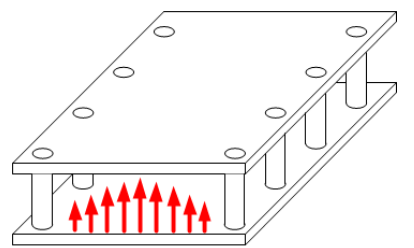

Figure 6: SIW with the dominant $\mathrm{TE}_{10}$ E-field distribution indicated

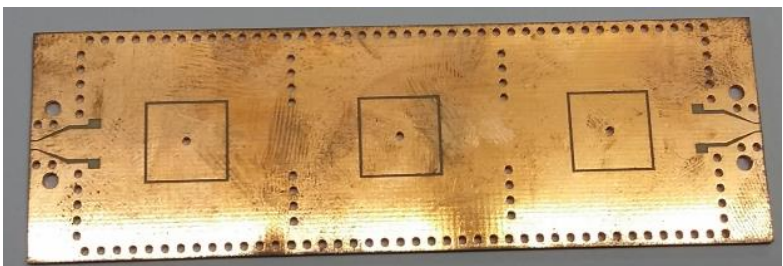

Figure 7: SIW filter with capacitively loaded resonators.

\section{CONCLUSION}

The context of wireless system design in developing economies leaves soft substrate system integration the most viable option for E-band development in the near future. Although some strides have been made in this area, this review has shown that the state-of-the-art still relies heavily on a multi-chip module approach using off-the-shelf MMICs. We have presented the benefits of having discrete mm-wave semiconductors available on the market, as well as proposed a new single-chip integration topology for future development. The state-of-the-art in integrating semiconductor devices in SIW at E-band frequencies has been shown to lag behind that 
in X-band, with the absence of specific circuit developments in SIW still prohibiting true E-band SIW system integration. Addressing these technology gaps will lead to more widespread development of E-band systems in conventional RF substrates and larger scale development in developing economies.

\section{ACKNOWLEDGMENT}

This work is supported by the National Research Foundation of South Africa (NRF) under Grants 92526 and 93921, as well as the Technology and Human Resources for Industry Programme (THRIP) under Grant 90224.

\section{REFERENCES}

[1] A. Touray, A. Salminen and A. Mursu, "ICT barriers and critical success factors in developing countries", Electron. J. Inform. Systems Developing Countries, vol. 56, pp. 1-7, 2013.

[2] M. D. J. Williams, Broadband for Africa: developing backbone commun. networks, Washington, D.C: World Bank, 2005.

[3] South African Department of Science and Technology, "Towards digital advantage: roadmapping South Africa's ICT RDI future”, 2015.

[4] D. Foty, B. Smith, S. Sinha, and M. Schroter, "Expanding wireless bandwidth in a power-efficient way: developing a viable mm-wave radio technology", in Proc. East-West Design \& Test Symp. (EWDTS), Rostov-on-Don, 2013, pp. 1-6.

[5] C. Sacchi, C. Stallo, and T. Rossi, "Space and frequency multiplexing for mm-wave multi-gigabit point-to-point transmission links", in Proc. IEEE Aerospace Conf. , Big Sky, MT, 2013, pp. 1-10.

[6] T. Stander, "A comparison of basic $94 \mathrm{GHz}$ planar transmission line resonators in commercial BiCMOS back-end-of-line processes", in Int. Conf. Actual Problems of Electron. Devices Eng. (APEDE), Saratov, 2014, pp. 185-192.

[7] ICASA. (2014, July 25). Frequency spectrum usage \& availability [Online]. Available: https://www.icasa.org.za/LegislationRegulations/EngineeringTechnolog y/RadioFrequencySpectrumManagement/FrequencySpectrumUsageand Availability/.

[8] V. Dyadyuk, J. D. Bunton, and Y. J. Guo, "Study on high rate long range wireless communications in the $71-76$ and $81-86 \mathrm{GHz}$ bands", in Proc. European Microwave Conf., Rome, 2009, pp. 1315-1318.

[9] T. S. Rappaport, R. Mayzus, Y. Azar, K. Wang, G. N. Wong, J. K. Schulz, M. Samimi, and F. Gutierrez, "Millimeter wave mobile communications for $5 \mathrm{G}$ cellular: it will work!", IEEE Access, vol. 1, pp. 335-349, 2013.

[10] V. C. Güngör, D. Sahin, T. Kocak, S. Ergüt, C. Buccella, C. Cecati, and G. P. Hancke, "Smart grid technologies: communication technologies and standards", IEEE Trans. Ind. Informat., vol. 7, no. 4, pp. 529-539, Nov, 2011.

[11] Y. Yan, Y. Qian, H. Sharif, and D. Tipper, “A survey on smart grid communication infrastructures: motivations, requirements and challenges", IEEE Commun. Surveys \& Tutorials, vol. 15, no. 1, pp. 520, 2013.

[12] J. A. van Schalkwyk and G. P. Hancke, "Energy harvesting for Wireless Sensors from electromagnetic fields around overhead power lines", in Proc. IEEE Int. Symp Ind. Electron., Hangzhou,2012, pp. 1128-1135.

[13] B. Fateh, M. Govindarasu, and V. Ajjarapu, "Wireless network design for transmission line monitoring in smart grid", IEEE Trans. Smart Grid, vol. 4, no. 2, pp. 1076-1086, Jun, 2013.

[14] H. Wang, Y. Qian, and H. Sharif, "Multimedia communications over cognitive radio networks for smart grid applications", IEEE Trans. Wireless Commun., vol. 20, no. 4, pp. 125-132, Aug, 2013.

[15] A. Aggarwal, S. Kunta, and P. K. Verma, "A proposed communications infrastructure for the smart grid", in Proc. Innovative Smart Grid Technologies Conf. (ISGT), Gothenburg, 2010, pp. 1-5.
[16] C. Vermeulen. "Eskom Telecommunications". EUTC Organised Workshop on Radio Spectrum, 21 March 2011

[17] F. Aalamifar, H. S. Hassanein, and G. Takahara, "Viability of powerline communication for the smart grid", in Proc. 26th Biennial Symp. Commun. (QBSC), Kingston, ON, 2012, pp. 19-23.

[18] M. Kang, B. Kim, W. Byun, and K. Kim, "Compact E-band single-chip transmitter using 0.1um GaAs pHEMT process", in Proc. 9th European Microwave Integrated Circuit Conf., Rome, 2014, pp. 285-288.

[19] J. Tarazi, M. C. Rodriguez, A. Dadello, M. G. McCulloch, A. P. Fattorini, S. Hwang, R. Clement, A. E. Parker, J. T. Harvey, and S. J. Mahon, "GaAs E band radio chip-set", in Proc. IEEE Compound Semiconductor Integrated Circuit Symp. (CSICS), Monterey, CA,2013, pp. 1-4.

[20] J. Antes, U. J. Lewark, A. Tessmann, S. Wagner, A. Leuther, T. Zwick, and I. Kallfass, "MMIC-based chipset for multi-gigabit satellite links in E-band", in Proc. IEEE Int. Conf. Wireless Inform. Technology and Syst. (ICWITS), Maui, HI, 2012, pp. 1-4.

[21] Y. Nakasha, S. Masuda, K. Makiyama, T. Ohki, M. Kanamura, N. Okamoto, T. Tajima, T. Seino, H. Shigematsu, K. Imanishi, T. Kikkawa, K. Joshin, and N. Hara, "E-band 85-mW oscillator and 1.3-W amplifier ICs using 0.12um GaN HEMTs for millimeter-wave transceivers", in Proc. IEEE Compound Semiconductor Integrated Circuit Symp. (CSIC), Monterey, CA, 2010, pp. 1-4.

[22] A. Margomenos, A. Kurdoghlian, M. Micovic, K. Shinohara, D. F. Brown, a. L. Corrion, H. P. Moyer, S. Burnham, D. C. Regan, R. M. Grabar, C. McGuire, M. D. Wetzel, R. Bowen, P. S. Chen, H. Y. Tai, A. Schmitz, H. Fung, A. Fung, and D. H. Chow, "GaN technology for E, W and G-band applications", in Proc. IEEE Compound Semiconductor Integrated Circuit Symp. (CSICS), La Jolla, CA, 2014, pp. 1-4.

[23] D. Zhao and P. Reynaert, "A 3 Gb/s 64-QAM E-band direct-conversion transmitter in 40-nm CMOS", in Proc. IEEE Asian Solid-State Circuits Conf. (A-SSCC), KaoHsiung, 2014, pp. 177-180.

[24] I. Nasr, R. Weigel, and D. Kissinger, "Broadband millimeter-wave receiver front-ends in silicon-germanium technology for multi-band communication systems", in Proc. IEEE MTT-S Int. Microwave Symp. Dig., Seattle, WA, 2013, pp. 1-3.

[25] O. Katz, R. Ben-Yishay, R. Carmon, B. Sheinman, F. Szenher, D. Papae, and D. Elad, "A fully integrated SiGe E-band transceiver chipset for broadband point-to-point communication", in Proc. IEEE Radio and Wireless Symp. (RWS), Santa Clara, CA, 2012, pp. 431-434.

[26] T. Kamgaing and V. R. Rao, "Passives partitioning for single package single chip SoC on 32nm RFCMOS technology", in Proc. IEEE MTT-S Int. Microwave Symp. Dig., Montreal, QC, 2012, pp. 1-3.

[27] M. Notten, H. Veenstra, X. Huang, and J. B. Mills, "A 60GHz LC-VCO module using flip-chip on a laminate substrate", in Proc. 39th European Microwave Conf. (EuMC), Rome, 2009, pp. 1768-1771.

[28] S. S. H. Hsu and H. Z. Zhu, "W-band multiple-ring resonator by standard 0.18um CMOS technology", IEEE Microwave Wireless Components Lett., vol. 15, no. 12, pp. 832-834, Dec, 2005.

[29] A. L. Franc, E. Pistono, D. Gloria, and P. Ferrari, "High-performance shielded coplanar waveguides for the design of CMOS $60-\mathrm{GHz}$ bandpass filters", IEEE Trans. Electron. Devices, vol. 59, no. 5, pp. 1219-1226, May, 2012.

[30] A. Nakayama, A. Fukuura, and M. Nishimura, "Millimeter-wave measurement of complex permittivity using dielectric rod resonator excited by NRD-guide", IEEE Trans. Microw. Theory Tech., vol. 51, no. 1, pp. 170-177, Jan, 2003.

[31] J. R. Long, Y. Zhao, W. Wu, M. Spirito, L. Vera, and E. Gordon, "Passive circuit technologies for mm-wave wireless systems on silicon", IEEE Trans. Circuits Syst., vol. 59, no. 8, pp. 1680-1693, Aug, 2012.

[32] D. Zelenchuk and V. Fusco, "Low insertion loss substrate integrated waveguide quasi-elliptic filters for V-band wireless personal area network applications”, IET Microwaves, Antennas \& Propagation, vol. 5 , no. 8, p. 921, Jun, 2011

[33] V. A. Karpovich, V. N. Rodionova, and VSkresanov, "Microwave, millimiter and submillimeter devices, instrumentation and equipment", in Proc. Int. Radar Symp., Wroclaw, 2008, pp. 1-3. 
[34] Millitech. (2015, Mar 23). Millitech - the leader in millimeter-wave technology and solutions. [Online]. Available: http://www.millitech.com/.

[35] SAGE Millimeter Inc. (2015, Mar 23). SAGE millimeter. [Online]. Available: http://www.sagemillimeter.com/.

[36] Eband Communications. (2015, Mar 23). Complete millimeter-wave solutions for today's most demanding networks. [Online]. Available: http://www.e-band.com/.

[37] Lightpointe. (2015, Mar 23). LightPointe official site. [Online]. Available: http://www.lightpointe.com/home.html

[38] Spacek Labs. (2015, Mar 23). Spacek Labs millimeter-wave technology. [Online]. Available: http://www.spaceklabs.com/cm/Home.html.

[39] VIVA TECH (2015, Mar 23). Millimetre wave, sub-millimeter wave / $\mathrm{THz}$ technology custom design \& development. [Online]. Available: http://www.vivatechmmw.com/

[40] F. Sagouo Minko, T. Stander, and P. J. Cilliers, "System architecture for a compact, low-cost $56-92 \mathrm{GHz}$ space based solar event observation instrument", in Proc. Int. Astronautical Congr., Jerusalem, 2015 (Accepted).

[41] N. Ghassemi, J. Gauthier, and Ke Wu, "Low-cost E-band receiver frontend development for gigabyte point-to-point wireless communications", in Proc. 43rd European Microwave Conf., Nuremberg, 2013, pp. 10111014.

[42] F. Alimenti, F. Placentino, A. Battistini, G. Tasselli, W. Bernardini, P. Mezzanotte, D. Rascio, V. Palazzari, S. Leone, A. Scarponi, N. Porzi, M. Comez, and L. Roselli, "A low-cost 24GHz Doppler radar sensor for traffic monitoring implemented in standard discrete-component technology", in Proc. European Radar Conf. (EURAD), Munich, 2007 , pp. $162-165$.

[43] M. Paillard, F. Bodereau, C. Drevon, P. Monfraix, J. L. Cazaux, L. Bodin, and P. Guyon, "Multilayer RF PCB for space applications: technological and interconnections trade-off", in Proc. 35th European Microwave Conf., Paris, 2005, vol. 3, pp. 1639-1642.

[44] F. Zhu, Z. Chen, J. Chen, W. Hong, and K. Wu, "A Ka-band transceiver front-end module for wide band wireless communication", in Proc. Int Conf. Computational Problem-Solving (ICCP), Chengdu, 2011, pp. 719-722.

[45] Hittite. (2015, Mar 23). Hittite Microwave. [Online]. Available: http://www.hittite.com/.

[46] Northrop Grumman. (2015, Mar 23). E-band products. [Online]. Available:

http://www.northropgrumman.com/BusinessVentures/Microelectronics/ Products/Pages/EBandProducts.aspx.

[47] GigOptix. (2015, Mar 23), GigOptix. [Online]. Available: http://www.gigoptix.com/.

[48] United Monolithic Semiconductors. (2013, Dec 18), UMS - MMICs solutions for III-V products, support \& foundry services. [Online]. Available: http://www.ums-gaas.com/phase-shifter.php.

[49] K. Tsukashima, M. Kubota, a Yonamine, T. Tokumitsu, and Y Hasegawa, "An E-band transmitter module constructed with four WLCSP MMICs solder-reflowed on PCB", in Proc. IEEE European Microwave Integrated Circuits Conf. (EuMIC), Amsterdam, 2012, pp. 207-210.

[50] L. Devlin, "The future of mm-wave packaging", Microw. J., vol. 57, no. 2, pp. 24-39, Feb, 2014

[51] K. Onodera, T. Ishii, S. Aoyama, S. Sugitani, and M. Tokumitsu, "Novel flip-chip bonding technology for W-band interconnections using alternate lead-free solder bumps", IEEE Microwave and Wireless Components Lett. (MWCL), vol. 12, no. 10, pp. 372-374, Oct, 2002.

[52] S. Song, Y. Kim, J. Maeng, H. Lee, Y. Kwon, and K. S. Seo, "A millimeter-wave system-on-package technology using a thin-film substrate with a flip-chip interconnection”, IEEE Trans. Adv. Packag., vol. 32, no. 1, pp. 101-108, Feb, 2009.

[53] V. Dyadyuk, L. Stokes, and T. Merkle, "Experimental evaluation of the E-band multi-chip modules integrated using laminated LCP substrates", in Proc. IEEE MTT-S Int. Microwave Workshop Series on Millimeter Wave Integration Technologies (IMWS), Sitges, 2011, pp. 53-56.
[54] V. Dyadyuk, M. Shen, and L. Stokes, "An E-band transceiver with 5GHz IF bandwidth", in Proc. 1st Australian Microwave Symp. (AMS), Melbourne, 2014, pp. 43-44.

[55] K. K. Samanta, D. Stephens, and I. D. Robertson, "Design and performance of a $60-\mathrm{GHz}$ multi-chip module receiver employing substrate integrated waveguides", IET Microwaves, Antennas \& Propagation, vol. 1, no. 5, p. 961, 2007.

[56] T. Kawasaki, M. Kubota, K. Tsukashima, T. Tokumitsu, and Y Hasegawa, "A full E-band low noise amplifier realized by using novel wafer-level chip size package technology suitable for reliable flip-chip reflow-soldering", in Proc. IEEE MTT-S Int. Microwave Symp. Dig., Tampa, FL, 2014, pp. 1-4

[57] D. a. Hill, D. G. Camell, K. H. Cavcey, and G. H. Koepke, "Radiated emissions and immunity of microstrip transmission lines: theory and reverberation chamber measurements", IEEE Trans. Electromagn. Compat., vol. 38, no. 2, pp. 165-172, May, 1996.

[58] Y. T. Lee, C. C. Chiong, D. C. Niu, and H. Wang, "A high gain E-band MMIC LNA in GaAs 0.1um pHEMT process for radio astronomy applications", in Proc. 9th European Microwave Integrated Circuit Conf., Rome, 2014, pp. 456-459.

[59] T. H. Lee and A. Hajimiri, "Oscillator phase noise: a tutorial", IEEE $J$. Solid-State Circuits, vol. 35, no. 3, pp. 326-335, Mar, 2000.

[60] TriQuint Semiconductor. (2013, Dec). TriQuint - Reach Further, Reach FasterTM - Discrete Transistors. [Online] Available: http://triquint.com/products/all/discrete-transistors.

[61] C. H. J. Poh, C. E. Patterson, S. K. Bhattacharya, S. D. Philips, N. E. Lourenco, J. D. Cressler, and J. Papapolymerou, "Packaging effects of multiple X-band SiGe LNAs embedded in an organic LCP substrate", IEEE Trans. Compon. Packag. Manuf. Technol., vol. 2, no. 8, pp. 13511360, Aug, 2012.

[62] R. B. Wu, T. M. Shen, and T. Y. Huang, "Development of millimeterwave passive components and system-in-packages by LTCC technology", in Proc. Asia-Pacific Microwave Conf.(APMC), Seoul,2013, pp. 113-115.

[63] R. Wanner and G. R. Olbrich, "A hybrid fabricated $40 \mathrm{GHz}$ low phase noise SiGe push-push oscillator", in Proc. Topical Meeting on Silicon Monolithic Integrated Circuits in RF Syst. Dig., Grainau, 2003, pp. 72 75 .

[64] Y. J. Cheng, W. Hong, and $\mathrm{K}$. Wu, "94 GHz substrate integrated monopulse antenna array", IEEE Trans. Antennas Propag., vol. 60, no. 1, pp. 121-129, Jan, 2012.

[65] E. Moldovan, R. G. Bosisio, and Ke Wu, "W-band multiport substrateintegrated waveguide circuits", IEEE Transactions on Microwave Theory and Techniques, vol. 54, no. 2, pp. 625-632, Feb. 2006

[66] K. S. Yang, S. Pinel, I. K. Kim, S. Member, and J. Laskar, "Low-loss integrated-waveguide passive circuits using liquid-crystal polymer system-on-package (SOP) technology for millimeter-wave applications", IEEE Trans. Microw. Theory Tech., vol. 54, no. 12, pp. 4572-4579, Dec, 2006.

[67] A. Bunea, M. Lahti, D. Neculoiu, A. Stefanescu, and T. Vaha-heikkila, "Investigation of substrate integrated waveguide in LTCC technology for mm-wave applications", in Proc. Asia-Pacific Microwave Conf. (APMC), Rome, 2011, no. 2, pp. 395-398.

[68] J. N. Smith and T. Stander, "An L-band tapered-ridge SIW-to-CPW transition", in Proc. Int. Conf. Actual Problems Electron. Devices Eng. (APEDE), Saratov, 2014, pp. 171-177.

[69] H. Zhang and W. Hong, "A wire bonding structure directly based on substrate integrated waveguide technology", IEEE Microwave and Wireless Components Lett., vol. 24, no. 11, pp. 757-759, Nov, 2014.

[70] M. Abdolhamidi and M. Shahabadi, "X-band substrate integrated waveguide amplifier", IEEE Microwave and Wireless Components Lett. vol. 18, no. 12, pp. 815-817, Dec, 2008 .

[71] F. F. He, K. Wu, W. Hong, L. Han, and X. Chen, "A low phase-noise VCO using an electronically tunable substrate integrated waveguide resonator", IEEE Trans. Microw. Theory Tech., vol. 58, no. 12, pp. 3452-3458, Dec, 2010. 